\title{
Australian Journal of \\ Genetic variability, heritability and genetic advance of soybean (Glycine max) genotypes based on yield and yield-related traits
}

\author{
Maletsema Alina Mofokeng
}

Agricultural Research Council-Grain Crops, Private Bag X 1251, Potchefstroom, 2520. South Africa

\author{
*Corresponding author: MofokengA@arc.agric.za
}

\begin{abstract}
The success of breeding programme relies on the variability present in the breeding material. Selection is also effective when there is significant amount of genetic variability among the individuals in a population. The study aimed at assessing genetic variability, heritability and genetic advance among yield and yield components of soybean genotypes. Eighty-two genotypes maintained at the Agricultural Research Council-Grain Crops were planted in an alpha lattice design, replicated twice in Potchefstroom and Brits in South Africa in 2017/18 growing season. Five plants per genotype were selected and yield and yield related traits were measured. Data were analysed through analysis of variance and genetic parameters were estimated. The results showed highly significant differences among the genotypes based on days to flowering, branch number per plant, hundred seed weight, pod weight per plant, pod length, seed number per plant, seed number per pod and grain yield. Heritability of yield and yield components were ranged from $5.9 \%$ to $100 \%$. The most heritable traits were hundred seed weight (100\%), days to flowering (64.13\%) and seed number per pod (67.37\%). The genotypic variance ranged from $0.3 \%$ to $33 \%$ while the phenotypic variation ranged from $1.5 \%$ to $44 \%$. The phenotypic and genotypic coefficient of variations was high for grain yield, medium for days to flowering and lowest for hundred seed weight. The phenotypic coefficient of variations (PCV) was higher than genotypic coefficient of variation (GCV) for all characters indicating the influence of environmental factors. The expected genetic advance was high for most of the traits, medium for seed number per pod and hundred seed weight and low for pod number per plant. The expected genetic advance as percent of mean was variable and high for all traits. There was vast variation observed among the soybean genotypes evaluated based on the yield and yield related traits.
\end{abstract}

Keywords: Genetic variation, GCV, PCV, soybean, yield.

\section{Introduction}

Soybean [Glycine max (L.) Merrill] belongs to genus Glycine. The genus Glycine wild is divided into two sub genera, Glycine and Soja. It is a diploidized allotetraploid $(2 n=40)$ and autogamous plant. North Eastern (Manchuria) region of the China is believed to be the center of origin and diversification center of the cultivated soybean. Soybean is one of the most important oil and legume crop grown globally. It grows in the tropics and sub-tropics for human and animal consumption as well as industrial purposes. It contains 40 to $42 \%$ good quality protein and 18 to $22 \%$ oil, which comprise $85 \%$ unsaturated fatty acids. The oil from soybean is free from cholesterol, so it is highly desirable in the human diet (Aslam et al., 1995). Besides fixing the atmospheric nitrogen, this crop has the ability to grow in a wide range of environments, to reduce soil erosion, to suppress weeds and to suit inter and sequential cropping patterns.

According to FAO (2020) soybean is produced worldwide in an area of 124921956 hectares and the production recorded in 2018 was 348712311 tonnes. The highest producers were United States of America followed by Brazil and Argentina. Of the total world production, America produced $87.2 \%$, Asia produced $9.3 \%$, Europe was $2.7 \%$, and $0.8 \%$ was produced in Africa. Africa's production was recorded to be 3556163 tonnes in area of 2614762 hectares in 2018. In South Africa, the production was estimated to be 1540,000 in the production area of 787200 hectares. Soybean is produced in almost all provinces of South Africa.

It is a valued finding to understand genetic diversity and relationship for facilitating the transfer of useful genes among cultivated species and to maximize the use of available germplasm resources. The extent of genetic diversity in germplasm can be assessed through morphological characterization. The characterized material then helps the plant breeders to select the accessions to be utilized in hybridization programme (Ghafoor et al., 2002). An investigation of genetic relatedness at a broad level may provide important information about the historical relationship among different genotypes. It reveals genetic backgrounds and relationships of germplasm and also provides strategies to establish, unitize and manage crop core collections (Brown-Guedira et al., 2000). Therefore, the knowledge of the genetic variation within accessions from germplasm collections is essential to the choice of strategies to incorporate useful diversity in the program, to facilitate the introgression of genes of interest in commercial cultivars, to understand the evolutionary relations among 
accessions, to better sample germplasm diversity, and to increase conservation efficiency (Fu, 2003).

Morphological characters have long been used to identify species and genera, to evaluate systematic relationships, and to discriminate between varieties (Smykal et al., 2008). In breeding practice and seed production, the role of morphological descriptors is very important, since the distinguishing between varieties can be done quickly and precisely. A few genes, thus easily observable and suitable for cultivar differentiation and identification, usually control qualitative traits. On the other hand, quantitative traits have more limitations in cultivar description, since they are affected by environment, developmental stage of the plant and the generation of selfing of breeding material. The quantitative traits include yield and yield parameters of which are observable for determination of yield performance of various genotypes. Their performance is also dependable on the environment and may be specific to a certain agro-ecology. Hence, determining the genetic parameters of genotypes is of paramount importance for parental selection and recommendations to the farmers.

For the effective selection of superior genotype to use in hybridization programme for the development of superior varieties, proper study of genetic variability due to genetic and non-genetic causes and other genetic parameters is necessary (Prasad et al., 2012). There has been many studies on genetic variation conducted by various researchers in soybean. Ravindra et al. (2017) and Baraska et al (2014) studied genetic variation on soybean yield and yield related traits where the authors estimated heritability, phenotypic and genotypic coefficient of variations, determination of genetic advance and genetic advance as a percent of mean. Neelima et al (2018) determined genetic variability, heritability and genetic advance on one hundred and twenty four soybean germplasm accessions. Genetic parameters like the genotypic coefficient of variation (GCV), phenotypic coefficient of variation (PCV), heritability and genetic advance (GA) are useful biometric tools for measuring genetic variability (Aditya et al., 2011). Hence, characterizing the genetic background of soybean and determining breeding values should be done before carrying out any improvement programme (Agong et al., 2001). The Agricultural Research Council-Grain Crops (ARC-GC) maintains more than two thousand soybean germplasm accessions in the gene bank. Some of the material has not been characterised for identification of good agronomic traits and yield parameters. Hence, the objective of the study was to assess genetic variability, heritability and yield and yield-related traits among soybean genotypes maintained by the ARC-GC.

\section{Results}

\section{Analysis of variance}

Results of analysis of variance for the nine agronomic traits for the eighty-two soybean genotypes are shown in Table 3. The data showed highly significant differences for site, genotype and their interaction for days to flowering, seed number per plant, and seed yield. Highly significant differences were also observed for site on branch number, pod number per plant, pod weight, seed number per plant, and seed yield per plant. Genotype was also significant for days to flowering, branch number, pod length, pod weight, seed number per pod, seed yield and seed number per plant. Highly significant differences were observed for site $x$ genotype for days to flowering and significant differences were recorded for seed number per plant and seed yield per plant.

\section{Variance components, coefficients of variation, heritability and genetic advance analyses}

Table 4 shows phenotypic, genotypic and environmental variances, and coefficient of variation, broad sense heritability and response to selection of the eighty-two soybean genotypes. Phenotypic variation ranged from 0.01 to 847.6. The phenotypic variation was high for grain yield per plant followed by days to flowering and lower in hundred seed weight. The genotypic variation was high for grain yield and lower for pod number per plant. It ranged from 0.00 to 4750.00 . The phenotypic variances were higher than the genotypic variances. The environmental variance ranged from 0.01 to 372.60 with grain yield being the highest followed by days to flowering and the lowest variance was observed in hundred seed weight. Phenotypic coefficient of variation ranged between 0.85 and 44.89 . The genotypic coefficient of variation also ranged between 0.84 and 33.60. The phenotypic and genotypic coefficients of variations were high for grain yield, followed by days to flowering and the lowest was hundred seed weight. Generally, the phenotypic variances of all the traits were higher than the genotypic variances indicating an influence of environmental effects in the expression of the traits to a certain extent.

Broad sense heritability $\left(\mathrm{H}^{2}\right)$ of the traits under study ranged from 5.88 to $100 \%$. The heritability was high for hundred seed weight $(100 \%)$, followed by seed number per pod $(67.37 \%)$ and days to flowering (64.13\%). The lowest heritability values were observed for pod number per plant $(5.88 \%)$, pod weight $(20.81 \%)$, seed number per plant (21.85\%) and branch number per plant (31.36\%). The genetic advance (GA) ranged from 2.63 to 3365.87 with grain yield being the highest, followed by days to flowering and the lowest value was recorded for pod number per plant. The percent of genetic advance (GAM) was highest for pod weight (31488.75), followed by grain yield (8002.22), and seed number per pod (2632.79) and lowest for pod number per plant (128.27). High genetic advance as a percent of mean coupled with high heritability were recorded for hundred seed weight, seed number per pod and days to flowering. High heritability values coupled with high genetic advance values was recorded for days to flowering.

\section{Clustering}

A dendrogram was constructed and the genotypes were grouped into five clusters (Figure 1). The first two clusters had one genotype each, PR 154-22 and Santa Rosa, which shows that they are distantly related with other genotypes. The fourth clusters consisted of two genotypes which were also closely related to each other but distantly related with the others. The genotypes were F 82-7145 and F 82-7824. The genotypes in cluster two and five were subdivided into sub-clusters with the closely related being grouped together and the others between the sub-clusters being distantly related.

\section{Discussion}

The highly significant mean squares due to genotypes signified the presence of variability within the genetic materials under investigation. The significant differences due to sites indicates differences of the climatic conditions of the selected sites and the responses of the material grown. 
Significant interaction of genotypes by sites indicated the existence of a wide range of variations among genotypes and between sites selected and that different genotypes reacted differently to varying environments. This suggests that there is enough reasons for selection of traits from among the different sources of planting materials for yield and yield component traits. Similarly, Narayanankutty et al. (2005), and Jandong et al. (2019) recorded highly significant variation in most yield parameters among the soybean genotypes signifying the existence variability. According to plant breeders, it is important to obtain great genetic variability for selection in plants, imposition results that in fact promote significant genetic gains (Bernardo, 2010; Cruz et al., 2011).

Generally, the phenotypic variances of all the traits were higher than the genotypic variances indicating an influence of environmental effects in the expression of the traits to a certain extent. These results concur with the report by Neelima et al. (2018) and Ravidra et al. (2017). According to Deshmukh et al. (1986), PCV and GCV values greater than $20 \%$ are regarded as high, whereas values less than $10 \%$ are considered low and values between $10 \%$ and $20 \%$ considered medium. The phenotypic and genotypic coefficients of variations were high for grain yield, medium for days to flowering and lowest for hundred seed weight. This is attributed to the preponderance of additive gene action and possesses high selective value and thus, selection pressure could profitably be applied on this character for their improvement (Neelima et al 2018). High magnitude of GCV observed in grain yield indicates the presence of wide variation to be allowed for further improvement by selection (Jandong et al., 2020). These results are in agreement with the findings by Jandong et al. (2020), Neelima et al (2018), Lukman et al (2014), Mahbub et al. (2015), and Pushpa et al. (2013). The PCV was found to be higher than GCV, which indicates the important role of environment in the expression of the characters. The slight differences of PCV and GCV were seen in almost all the characters except the grain yield. This shows that the influence of environmental factors on the performance of phenotype is low (Aditya et al., 2011; Malek et al., 2014). Akram et al. (2016) stated that the low environmental factor causes a selection based on those characters would be effective. Other authors also reported small differences between the PCV and GCV (Mahbub et al., 2015; Nirmaladevi et al., 2015). The results of the phenotypic and genetic coefficient of variation show presence and wide genetic variation existing among the soybean genotypes maintained by the ARC-GC.

Heritability estimates are considered in understanding the pattern of inheritance of quantitative character like seed yield and yield components. Similarly, genetic advance is also a useful measure to predict gain in specified selection intensity. However, when it is considered along with heritability becomes more valuable to predict response to selection than the heritability estimates alone (Johnson et al., 1955). In this study, heritability was high for hundred seed weight, seed number per pod and days to flowering, which concurs to the reports from the study by Aditya et al. (2011), Aditya et al. (2011), Osekita and Olorunfemi (2014) and Kwusantoro et al. (2018). The high estimate of broad sense heritability revealed that the characters could be effectively used for cultivar development and hybridization program. Heritable variation of different yield parameters is useful for permanent genetic improvement (Singh, 2000). The most important function of heritability in the genetic study of quantitative characters is its predictive role to indicate the reliability of the phenotypic value as a guide to breeding value (Dabholkar, 1992; Falconer and Mackay, 1996). High heritability estimates for some of the phenotypic traits indicate less influence of environments, and so there is a good chance for the improvement of these traits through direct selection (Kumar et al., 2012).

Genetic advance measures the expected genetic progress that would result from selecting the best performance genotypes for a given characters (Allard, 1960). The genetic gain that can be obtained for a particular trait through selection is the product of its heritability, phenotypic standard deviation and selection differential (Burton, 1952). High heritability coupled with high genetic advance was observed for days to flowering, on the other hand, high heritability coupled with low genetic advance were observed for hundred seed weight and seed number per pod. High genetic advance as a percent of mean coupled with high heritability were recorded for hundred seed weight, seed number per pod and days to flowering. High heritability values coupled with high genetic advance values was recorded for days to flowering, which suggested that this trait can be considered as a favourable attribute for the improvement through selection and this may be due to additive gene action Panse (1957) and thus, could be improved upon by adapting selection without progeny testing. Additionally, high heritability values coupled with low genetic advances were recorded for hundred seed weight and seed number per pod revealing the predominance of non-additive gene action. High heritability coupled with high genetic advance as a percent of mean was recorded for hundred seed weight, seed number per pod and days to flowering. Similar results were reported by Bangar et al. (2003), Hina Kausar et al. (2005), Abady et al. (2013), Chandel et al. (2013), Amit et al. (2014), Mahbub et al. (2015), Yadawad et al. (2015) and Savita and Koti (2016). The estimate of heritability along with genetic advance gives the idea about the genetic architecture of the population. Several researchers (Baraskar et al., 2014; Chandrawa et al., 2017; Malek et al., 2014; Mishra et al., 2015; and Reni and Rao, 2013) have also calculated genotypic and phenotypic components of variance, heritability and genetic advance for different yield characters in soybean. The authors revealed that selection was effective for a population with broad genetic variability and character with high heritability. Heritability provides useful information on the magnitude of the inheritance of traits from original parents to their progenies, while genetic advance is helpful in finding the actual genetic gain expected under selection (Larik et al., 2000, Nwangburuka and Denton, 2012, Ogunniyan and Olakojo, 2015).

The most diverse genotypes were PR 154-22, Santa Rosa, F 82-7145 and Vicoja among others. Clustering of genotypes aid in selecting the most diverse genetic material, potential parents for hybridization and for transgressive segregation and prospects of getting high hetersosis. Many authors have used clustering in soybean for assessment of presence of genetic diversity (Marconato et al., 2016; Ibiduni et al., 2020). The findings in this study concur with the reports given by Ojo et al., (2012) and Dayaman et al. (2009) who found six cluster groups among 45 genotypes of soya bean and Mehetre et al. (1994) who reported nine distinct clusters in 43 accessions of soya bean. 
Table 1. Agro-morphological characters measured in the study.

\begin{tabular}{|c|c|c|}
\hline Trait & Abbreviation & Description \\
\hline Days to $50 \%$ flowering & DFW & $\begin{array}{l}\text { The number of days from date of sowing to the stage where } 75 \% \text { of } \\
\text { the buds have fully flowered. }\end{array}$ \\
\hline Branch number & BRN & Number of branches counted per plant \\
\hline Hundred seed weight (g) & HSW & Weight of hundred seeds measured in grams \\
\hline Pod Number per plant & PNP & Number of pods produced per plant \\
\hline Pod weight (g) & PWT & Weight of pods produced per plant \\
\hline Pod length (mm) & PDL & Length of the ten selected pods per plant \\
\hline Seed number per pod & SNP & Number of seeds produced per pod \\
\hline Seed number per plant & SNT & Number of seeds produced per plant \\
\hline Yield per plant (g) & GYD & Total weight of seeds per plant. \\
\hline
\end{tabular}

Table 2. List of germplasm used in the study.

\begin{tabular}{|c|c|c|c|}
\hline Serial Number & Genotype & Serial Number & Genotype \\
\hline 1 & 12950 & 42 & Hernon \\
\hline 2 & $14 / 6 / 32$ & 43 & HERON \\
\hline 3 & $165 / 5$ & 44 & IBIS \\
\hline 4 & $21 / 6 / 23 / 2$ & 45 & Impala \\
\hline 5 & 23545 & 46 & Jackson \\
\hline 6 & 26090 & 47 & Jupiter \\
\hline 7 & $28 / 6 / 54$ & 48 & Mack 6 \\
\hline 8 & 40913 & 49 & Maksura \\
\hline 9 & 42897 & 50 & Mojiana \\
\hline 10 & 42912 & 51 & MTD 63 \\
\hline 11 & 44000 & 52 & N69-2774 \\
\hline 12 & 44007 & 53 & ND 85 \\
\hline 13 & $54 \mathrm{~S} 116$ & 54 & ORIBI \\
\hline 14 & 54 S 219 & 55 & PI 170889/(R56-49) \\
\hline 15 & 54 S 95 & 56 & PR 133 (484) \\
\hline 16 & $69 \mathrm{~S} 10$ & 57 & PR 144-4 \\
\hline 17 & 69 S 13 Seleksie & 58 & PR 144-9 \\
\hline 18 & 69 S 19 & 59 & PR 145-2 \\
\hline 19 & $85 / 05 /$ & 60 & PR 154-13 \\
\hline 20 & $89 / 05 /$ & 61 & PR 154-14 \\
\hline 21 & AGS 239 & 62 & PR 154-22 \\
\hline 22 & B 66 S 365 & 63 & PR 154-47 \\
\hline 23 & B 66S 385 & 64 & PR 164-20 \\
\hline 24 & Chippewa 63 & 65 & PR 164-22 \\
\hline 25 & Coc Chum & 66 & PR 165-3 \\
\hline 26 & Columbia M 8 A & 67 & PR 165-31 \\
\hline 27 & Crawford & 68 & PR 165-50 \\
\hline 28 & D64-4636 & 69 & PR 165-52 \\
\hline 29 & D66-8666 & 70 & R 5-4-2 M \\
\hline 30 & DB 1601 & 71 & Rhosa ligte hilum \\
\hline 31 & DUNDEE & 72 & S4-A,P,4 \\
\hline 32 & EGRET & 73 & Santa Rosa \\
\hline 33 & Essex & 74 & Shelby \\
\hline 34 & F 82-7145 & 75 & Soja (pautena) \\
\hline 35 & F 82-7656 & 76 & SSS 2 \\
\hline 36 & F 82-7824 & 77 & SSS 3 \\
\hline 37 & Grant & 78 & TN 81-46 \\
\hline 38 & Gx Gous & 79 & UFV-1 \\
\hline 39 & Hampton 266 A & 80 & Vicoja \\
\hline 40 & Hawkeye & 81 & Yeluanda \\
\hline 41 & Hawkeye (USSR) & 82 & Yubelejuaja \\
\hline
\end{tabular}




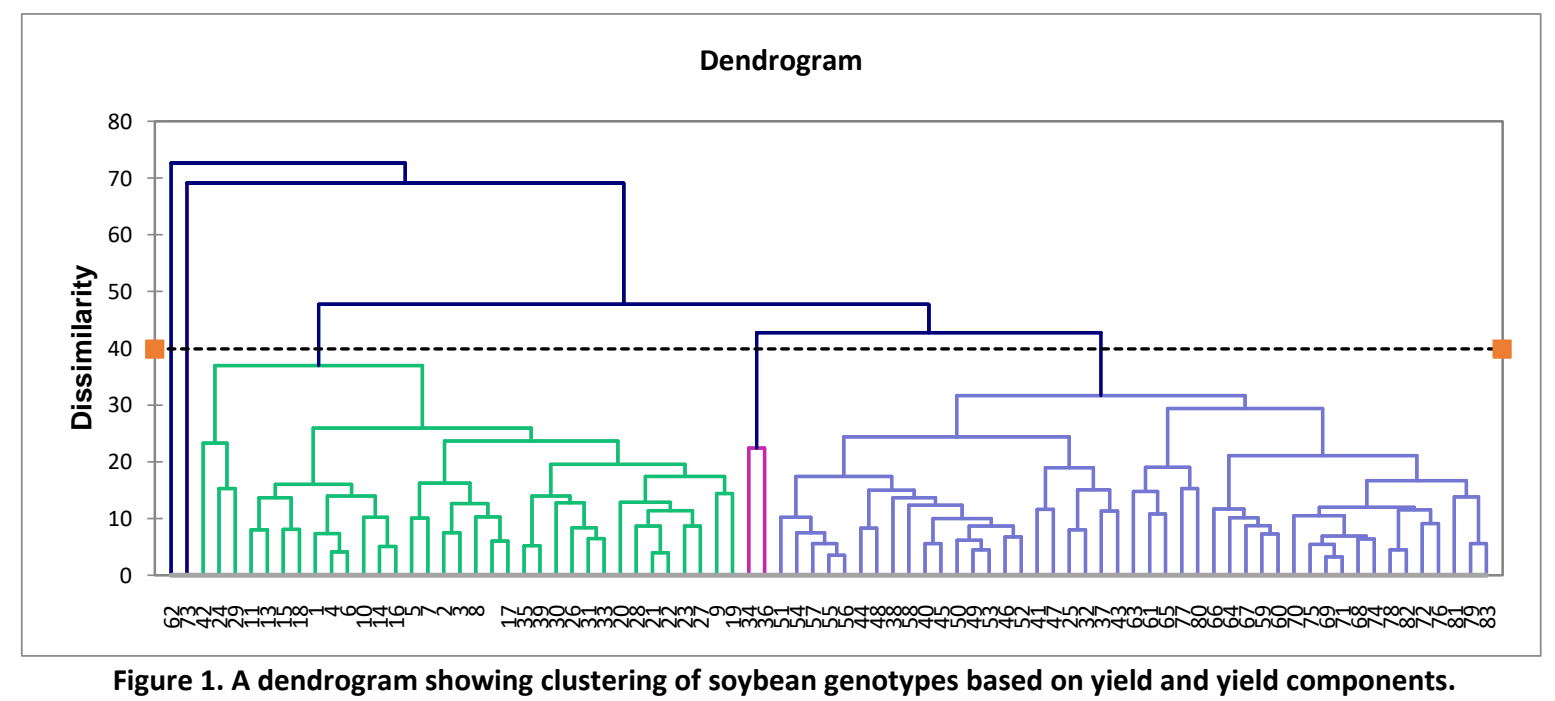

\begin{tabular}{|c|c|c|c|c|c|c|c|c|c|c|}
\hline SOV & DF & DFL & HSW & BRN & PDL & PNP & PWT & SNT & SNP & SYD \\
\hline Site & 1 & $56195.97 * * *$ & $145.5 n s$ & $38.694 * * *$ & $10.80 \mathrm{~ns}$ & $175456 * * *$ & $81304.0^{* * *}$ & $1398926 * * *$ & $0.0000 n s$ & $38338.5^{* * *}$ \\
\hline Genotype & 81 & $276.42^{* * *}$ & $248.7 \mathrm{~ns}$ & $3.710 * * *$ & $37.48^{* *}$ & 5951ns & $1283.9 * * *$ & 13898* & $0.5079 * * *$ & $691.5^{* *}$ \\
\hline Site*genotype & 89 & $188.89 * * *$ & $186.3 \mathrm{~ns}$ & $1.919 \mathrm{~ns}$ & $24.83 n s$ & $5632 n s$ & $1144.5 n s$ & $15209 * *$ & $0.0000 n s$ & $670.7 * *$ \\
\hline Residual & 143 & 66.55 & 234.2 & 2.474 & $22.73 n s$ & 6546.0 & 876.5 & 9799 & 0.1572 & 425.7 \\
\hline
\end{tabular}

Table 4. Phenotypic, genotypic and environmental variances and coefficient of variation, broad sense heritability and response to selection of the nine yield related traits of soybean genotypes.

\begin{tabular}{|lllllllll|}
\hline Trait & & & & & & & & \\
& $\delta_{2} \mathrm{p}$ & $\delta_{2} \mathrm{~g}$ & $\delta_{2} \mathrm{e}$ & $\mathrm{PCV}$ & $\mathrm{GCV}$ & $\mathrm{H}^{2}$ & $\mathrm{GA}$ & GAM \\
\hline HSW & 0.01 & 0.01 & 0.01 & 0.85 & 0.84 & 100.00 & 19.41 & 1545.73 \\
\hline DFW & 168.63 & 108.14 & 60.49 & 15.51 & 12.42 & 64.13 & 1717.93 & 2450.50 \\
\hline BRN & 2.95 & 0.93 & 2.03 & 7.36 & 4.12 & 31.36 & 111.17 & 2037.82 \\
\hline PNP & 0.05 & 0.00 & 0.04 & 1.51 & 0.37 & 5.88 & 2.63 & 128.27 \\
\hline PWT & 0.06 & 0.01 & 0.04 & 1.81 & 0.82 & 20.81 & 550.84 & 31488.75 \\
\hline PDL & 21.05 & 5.6 & 15.45 & 7.36 & 3.79 & 26.60 & 251.80 & 647.77 \\
\hline SNP & 0.28 & 0.19 & 0.09 & 3.17 & 2.59 & 67.37 & 73.52 & 2632.79 \\
\hline SPT & 0.06 & 0.01 & 0.04 & 1.56 & 0.73 & 21.85 & 10.63 & 466.48 \\
\hline YDP & 847.60 & 475.00 & 372.60 & 44.89 & 33.60 & 56.04 & 3365.87 & 8002.22 \\
\hline
\end{tabular}




\section{Plant material, trial layout and management}

Eighty-two genotypes maintained by the Agricultural Research Council-Grain Crops are shown in Table 2. The genotypes were planted in 2017/18 growing season in Potchefstroom $\left(26.7145^{\circ} \mathrm{S} .27 .0970^{\circ} \mathrm{E}\right)$ and Brits $\left(25.6100^{\circ}\right.$ S. $\left.27.7960^{\circ} \mathrm{E}\right)$ in the North West Province of South Africa. The trials were laid out in alpha lattice designs replicated two times. Each plot consisted of two $4 \mathrm{~m}$ length rows with a spacing of $75 \mathrm{~cm}$ between the rows and $10 \mathrm{~cm}$ between the plants. Fertilizer 2:3:4 was applied before planting. The plants were irrigated using sprinklers three times a week. The pre- and post-emergent herbicides (Metagan and Basagran) were used to control the weeds as well as manual weeding. Lime Ammonium Nitrate was top dressed 45 days after germination, before the plants flower. The cultural practices were applied as per soybean planting recommendations.

\section{Data Collection}

Five plants were evaluated from each replication of each genotype. The characters shown in Table 1 were measured.

\section{Data Analysis}

Analysis of variance was performed for all traits in order to test the significance of variation among the genotypes using GenStat version 18. The replications and blocks were treated as fixed factors whereas genotypes, environment and their interactions were treated as random factors. The linear model used for data analysis was:

$$
Y i j k l=\mu+G i+E j+R k(j)+B l(j k)+G E i j+\varepsilon i j k l
$$

Where, Yijkl is the observed value of genotype I in block I and replication $\mathrm{k}$ of environment $\mathrm{j}, \mu$ is the grand mean, $\mathrm{Gi}$ is the effect of genotype $\mathrm{i}, \mathrm{Ej}$ is the environment or location effect, $R k(j)$ is the effect of replication $k$ in environment $j$, $\mathrm{Bl}(\mathrm{jk})$ is the effect of block I in environment $\mathrm{j}$ and replication k, GEij is the interaction effect of genotype I with environment $j$, and $\varepsilon i j k l$ is the error (residual) effect of genotype I in block I and replication $k$ of environment $\mathrm{j}$. A dendrogram was constructed using RStudio in $\mathrm{R}$ statistical package.

The genetic parameters including genotypic and phenotypic variance components and coefficient of phenotypic and genotypic variability were estimated according to Burton (1951) and Singh and Chaudhary (1985). The formulae are as follows:

$\delta 2 g=M S e-M S g / r$

Where: $M S g$ = mean square due to genotypes,

$M S e=$ error mean square

$r=$ the number of replication

$$
\text { Environmental variance }(\delta 2 e)=\text { error mean square }
$$$$
=M S e
$$

Phenotypic variance $\left.\left(\boldsymbol{\delta}^{2} \mathrm{~g}\right)=\boldsymbol{\delta}^{2} \mathrm{~g}+\boldsymbol{\delta}^{2} \mathrm{e}\right)$

Phenotypic coefficient of variance $(P C V)$

$$
=\frac{\mathbb{G} \sqrt{\delta 2 p}}{x m e a n} x 100
$$

Genotypic coeffcient of variation (GCV)

$$
=\frac{\sqrt{\delta 2 g}}{\text { xmean }} \times 100
$$

Where: xmean $=$ grand mean of a character
Heritability $\left(\mathrm{H}^{2}\right)$ : heritability in broad sense for all characters was computed using the formula given by (Falconer et al., 1996).

Heritability $(H 2)=\frac{\delta 2 g}{\delta 2 p} \times 100$

Where: $\mathrm{H}^{2}=$ heritability in broad sense

$$
\begin{aligned}
& \bar{\sigma}_{P}=\text { Phenotypic variance } \\
& \sigma^{\bar{\sigma}}{ }^{2}=\text { Genotypic variance }
\end{aligned}
$$

Genetic advance in absolute unit (GA) and percent of the mean (GAM), assuming selection of superior $5 \%$ of the genotypes was estimated in accordance with the methods illustrated by Johnson et al. (1955) as:

$G A=K \delta P H 2$

Where: $\mathrm{K}=$ the standardized selection differential at $5 \%$ selection intensity $(k=2.06)$

$\mathrm{s}_{\mathrm{p}}=$ phenotypic standard deviation on mean basis $\mathrm{H}^{2}=$ heritability in broad sense

Genetic advance as percent of mean was calculated to compare the extent of predicted advance of different traits under selection, using the following formula:

$G A M=\frac{G A}{X} x 100$

Where: $\mathrm{GAM}=$ genetic advance as percent mean $\mathrm{GA}=$ genetic advance under selection

$\overline{T^{-}}=$Mean of the population in which selection employed

\section{Conclusions}

Analysis of variance revealed enormous genetic variability among the soybean genotypes studied. The phenotypic and genotypic coefficients of variations were high for grain yield, medium for days to flowering and lowest for hundred seed weight. This was attributable to the preponderance of additive gene action and possession of high selective value and thus, selection pressure could profitably be applied on these characters for further improvement. The phenotypic coefficient of variations (PCV) were higher than genotypic coefficient of variation (GCV) for all characters indicating the influence of environmental factors. High estimates of heritability coupled with high genetic advance and genetic advance as a percent of mean were recorded for days to flowering, hundred seed weight, and seed number per pod. The high estimate of broad sense heritability revealed that the characters could be effectively used for cultivar development and hybridization programmes. The expected genetic advance was high for most of the traits, medium for seed number per pod and hundred seed weight and low for pod number per plant. The expected genetic advance as percent of mean was high for all traits. There was vast variation observed among the genotypes.

\section{Acknowledgement}

Department of Science and Innovation of South Africa is appreciated for funding the study. 


\section{References}

Abady S, Fitsum M., Zinaw D (2013) Heritability and path coefficient analysis in soybean (Glycine max (L.) Merrill.) genotypes at Pawe, North Western Ethiopian J Environ Sci Water Res. 2(8):270-276.

Aditya JP, Pushpendra B, Anuradha B (2011). Genetic variability, heritability and character association for yield and component characters in soybean (G. $\max$ (L.) Merrill). J Central Eur Agric. 12(1):27-34.

Akram S, Hussain BMN, Bari MAA, Burritt DJ, Hossain MA (2016) Genetic variability and association analysis of soybean (Glycine max (I.) Merrill) for yield and yield attributing traits. Plant Genet Trait 7(13):1-11.

Allard RW 1960. Principles of Plant Breeding. John Willey and Sons, New York.

Amit K, Avinash P, Chubasenla A (2014). Evaluation of genetic diversity and interrelationships of agromorphological characters in soybean genotypes (Glycine max (L.) Merrill.). Proc of Natl Acad Sci.. India, Sect B, Biological Science 11-14.

Baraskar VV, Kachhadia VH, Vachhanl JH, Barad HR, Pate MB, Darwankar MS (2014). Genetic variability, heritability and genetic advance in soybean [Glycine $\max$ (L.) Merrill]. Electr J Plant Breed 5(4):802-806.

Bernardo R (2010) Breeding for quantitative traits in plants. Stemma Press, Woodbury.

Burton GM (1952) Quantitative inheritance in grasses. Proc Int Grassl Cong 1:277-285.

Brown-Guedira GL, Thompson JA, Nelson RL, Warburton ML (2000) Evaluation of genetic diversity of soybean introductions and north American ancestors using RAPD and SSR markers. Crop Sci. 40:815-823.

Chandel KK, Patel NB, Kulkarni GU (2013) Genetic divergence studies in soybean (Glycine max (L.) Merill.). Soc Sci and Dev Agric Technol. 645-649.

Cruz CD, Ferreira FM, Pessoni LA (2011) Biometria aplicada ao estudo da diversidade genética. Suprema, Visconde do Rio Branco.

Dabholkar AR (1992). Elements of Biometrical Genetics. New Delhi, India: Concept Publishing Company.

Dayaman V, Senthil N, Raveendran M, Nadarajan N, Shanmugasundaram P, Balasubramanian P (2009) Diversity analysis in selected indian soya bean [Glycine max (L.) Merrill] using morphological and SSR markers. Int J Integr Biol. 5:125-129.

Falconer, D.S., Trudy, F.C. M. (1996). Introduction to Quantitative Genetics, $4^{\text {th }}$ Edn.

Fu Y-B (2003). Applications of bulking in molecular characterization of plant germplasm: a critical review. Plant Genet Res. 1:161-167.

Ghafoor A, Zahoor A, Qureshi AS, Bashir M (2002) Genetic relationship in Vigna mungo (L.) Hepper and $V$. radiata (L.) R. Wilczek based on morphological traits and SDS-PAGE. Euphytica 123:367-2002.

Ibidunni SA, Omolayo JA, Olabisi A, Sunday OO (2020) Agronomic Potential and Genetic Diversity of 43 Accession of Tropical Soybean (Glycine $\max (\mathrm{L})$ Merrill). Int J Plant Res 10(2):33-39.

Jandong EA, Uguru MI, Okechukwu EC (2020) Estimates of genetic variability, heritability and genetic advance for agronomic and yield traits in soybean (Glycine max L.). Afr J Biotechnol. 19(4): 201-206.
Johnson HW, Robinson HF, Comstock RE (1955) Estimates of genetic and environmental variability in soybeans. Agron J. 47:314-318.

Kumar S, Nakajima T, Mbonimpa EG, Gautam S, Somireddy UR, Kadono A, Fausey N (2014) Long-term tillage and drainage influences on soil organic carbon dynamics, aggregate stability, and carbon yield. Soil Sci Plant Nutr. 60(1):108-118.

Kuswantoro $H$, Artari R, Rahajeng W, Ginting E, Supeno A (2018) Genetic variability, heritability, and correlation of some agronomical characters of soybean varieties. Biosaintifika: J Biol Biol Edu. 10(1): 9-15.

Lukman HS, Eman P (2014) Genetic Variability, heritability and expected genetic advances of quantitative characters in $F_{2}$ progenies of soybean crosses. Indon J Agric Sci. 15:1116.

Larik AS, Malik SI, Kakar AA, Naz MA (2000) Assessment of heritability and genetic advance for yield components in $G$. hirsutum. Sci Khyber 13(1):39-44

Mahbub MM, Mamunur MR, Hossain MS, Mahmud F, Mir Kabir MM (2015) Genetic variability, Correlation and Path analysis for yield and yield contributing components in soybean. Amer-Eur J Agric Environ Sci. 15(2):231-236.

Malek MA, Rafii MY, Afroz MSS, Nath UK, Mondal MMA (2014) Morphological characterization and assessment of genetic variability, character association, and divergence in soybean mutants. Scient World J. 12.

Marconato MB, Pereira EM, Silva FM, Bizari EH, Pinheiro JB, Mauro AO, Unêda-Trevisoli SH (2016) Genetic divergence in a soybean (Glycine max) diversity panel based on agromorphological traits. Genet Mol Res. 21(4):15.

Mehetre SS, Mahajan CR, Patil PA, Gohatage RD (1994) Genotypic and phenotypic variability and heritability of some quantitative characters in soya bean (Glycine max L.). Ann Agric Res.15(1):41-44.

Nwangburuka CC, Denton OA (2012) Heritability, character association and genetic advance in six agronomic and yield related characters in leaf Corchorus olitorius. Int J Agric Res. 7:367-375.

Neelima G, Mehtre SP, Narkhede GW (2018) Genetic Variability, heritability and genetic advance in soybean. Int J Pure Appl Biosci. 6(2):1011-1017.

Nirmaladevi G, Padmavathi G, Kota S, Babu VR (2015) Genetic variability, heritability and correlation coefficients of grain quality characters in rice (Oryza sativa I.). Sabrao J Breed Genet. 47(4):424-433.

Ogunniyan DJ, Olakojo SA (2015) Genetic variation, heritability, genetic advance and agronomic character association of yellow elite inbred lines of maize (Zea mays L.). Niger J Genet. 28:24-28.

Ojo DK, Ajayi AO, Oduwaye OA (2012) Genetic Relationships among soya bean accessions based on morphological and RAPDs techniques. Pertanika J Trop Agric Sci. 35:237-248.

Osekita O.S, Olorunfemi O (2014) Quantitative genetic variation, heritability and genetic advance in the segregating $\mathrm{F}_{3}$ populations in soybean (Glycine max (L.) Merril. Int J Adv Res. 2(7):82-89.

Panse VG (1957) Genetics of quantitative characters in relation to plant breeding. Indian J Genet Plant Breed. 17:318-328.

Ravindra KJ, Arunabh J, Hem RC, Abhay D, Champa LK (2017) Study on genetic variability, heritability and genetic advance in soybean [Glycine max (L.) Merrill]. Legume Res. (41):532-536 
Sahay G, Sharma BK, Anna DA (2005) Genetic variability and interrelationship in F2 segregating generation of soybean (Glycine max (L.) Merrill) in mid altitude of Meghalaya. Agric Sci Digest. 25(2):107-110.

Savita FH, Koti RV (2016) Studies on genetic parameters for yield and yield contributing traits in soybean (Glycine max L.). The Bioscan. 11(2):1127-1129.

Singh RK, Chaudhary BD (1985) Biometrical methods in quantitative genetic analysis. Kalyani Publishers, New Delhi, India, pp. 39-78.
Singh BD (2000) Plant breeding: principles and methods. Kalyani Publishers, New Delhi.

Yadawad A, Hanchinal RR, Nadaf HL, Desai SA, Biradar S, Naik VR (2015). Genetic variability and heritability estimates for yield attributes and leaf rust resistance in $F_{3}$ population of wheat (Triticum aestivum L.). The Bioscan. 10(2):935-938 